\title{
Expression and fast preparation of biologically active recombinant human coagulation factor VII in CHO-K1 cells
}

\author{
W. Xiao, C.Q. Li, X.P. Xiao and F.Z. Lin \\ Institute of Blood Transfusion, Chinese Academy of Medical Sciences, \\ Chengdu, Sichuan, China \\ Corresponding authors: F.Z. Lin / W. Xiao \\ E-mail: 1fangzhao@126.com / bio_xiaowei@hotmail.com
}

Genet. Mol. Res. 12 (4): 6813-6824 (2013)

Received July 30, 2013

Accepted November 27, 2013

Published December 16, 2013

DOI http://dx.doi.org/10.4238/2013.December.16.7

\begin{abstract}
Human coagulation factor VII (FVII) plays an important role in the blood coagulation process and exists in micro amounts in human plasma; therefore, any attempt at the large-scale production of FVII in significant quantities is challenging. The purpose of this study was to express and obtain biologically active recombinant FVII (rFVII) from Chinese hamster ovary K1 (CHO-K1) cells. The full-length FVII cDNA was isolated from a HepG2 cell line and then subcloned in pcDNA3.1 to construct an expression vector, pcDNAFVII. CHO-K1 cells were transfected with $1 \mu \mathrm{g}$ pcDNA-FVII. The cell line that stably expressed secretory FVII was screened using $900 \mu \mathrm{g} /$ $\mathrm{mL}$ G418. The FVII copy number in CHO-K1 cells was detected by quantitative polymerase chain reaction (qPCR). The rFVII was purified in ligand affinity chromatography medium. The purified protein was detected by sodium dodecyl sulfate-polyacrylamide gel electrophoresis (SDS-PAGE) and Western blot analysis. The biological activity of the purified FVII protein was determined by a prothrombin time assay. Three cell lines that permanently expressed rFVII were screened. The
\end{abstract}


qPCR results demonstrated that each CHO-K1 cell harbored two FVII DNA copies. The SDS-PAGE and Western blot analysis showed that the purified protein was about $50 \mathrm{kDa}$. The purity of the target protein was $95 \%$. The prothrombin time assay indicated that the FVII-specific activity of rFVII was $2573 \pm 75 \mathrm{IU} / \mathrm{mg}$. This method enabled the fast preparation of high-purity rFVII from CHO-K1 cells, and the purified protein had good biological activity.

Key words: Human coagulation factor VII; Specific activity; Quantitative polymerase chain reaction; Ligand affinity chromatography

\section{INTRODUCTION}

Human coagulation factor VII (FVII) is a vitamin K-dependent single-chain glycoprotein, which induces the generation of fibrin during the coagulation process (O'Hara et al., 1987). FVII plays an important role in the blood coagulation process, and is one of the key molecules involved in blood clot formation. FVII can be secreted into the blood and circulated in a zymogen form (Kisiel and Davie, 1975; Radcliffe et al., 1977). It is converted to activated FVII (FVIIa) by Xa, XIIa, IXa, or thrombin. FVIIa initiates the extrinsic coagulation pathway by binding tissue factors on the surface of cells (Kisiel et al., 1977; Seligsohn et al., 1979). Previous studies have demonstrated that FVIIa can be used for the treatment of congenital F deficiency, impaired liver function, thrombocytopenia and dysfunction, operation period of acute hemorrhage, hemophilia and inhibitors in hemophilia, etc. (Hedner and Lee, 2011). FVIIa has attracted a lot of attention due to its wide applications. FVII exists in micro amounts $(200-400 \mathrm{ng} / \mathrm{mL})$ in human plasma; therefore, any attempt at the large-scale production of FVII in significant quantities is challenging. This has important implications for carrying out research on the expression of recombinant FVII (rFVII) in mammalian cells.

\section{MATERIAL AND METHODS}

\section{Plasmids and bacteria}

The plasmid pcDNA3.1 (Invitrogen, USA) was used for expressing FVII in Chinese hamster ovary K1 (CHO-K1) cells. The vector pMD18-T (TAKARA, Japan) was used to subclone FVII fragments for sequencing. The Escherichia coli DH5a bacterium strain (Invitrogen) was used as a host for constructing the recombinant plasmid.

\section{Cell culture}

A human hepatoma cell line (HepG2) and the CHO-K1 cell lines were obtained from the Cell Bank of Shanghai, Chinese Academy of Sciences. HepG2 cell lines were grown in Dulbecco's modified Eagle's medium (DMEM, Gibco, USA) containing 10\% fetal bovine serum (FBS, Gibco), and CHO-K1 cell lines were cultured in Ham's F-12K medium (Gibco) containing 10\% FBS. 


\section{Cloning of FVII cDNA and construction of the expression plasmid}

The HepG2 cell line was used as a source of the human FVII gene. RNA was obtained using an RNA extraction kit (Invitrogen). Full-length human FVII cDNA was isolated using specific primers by reverse transcription-polymerase chain reaction (RT-PCR). RT-PCR was performed in a two-step reverse transcription Kit (TAKARA). The specific primers used for cloning the FVII gene were as follows: F1, 5'-CACCATGGTCTCCCAGGCCCTCAGGCTC C-3' and R1, 5'-CGGGATATCCTAGGGAAATGGGGCTCGC-3'.

The PCR procedure involved initial denaturation of $95^{\circ} \mathrm{C}$ for $3 \mathrm{~min}$, followed by $94^{\circ} \mathrm{C}$ for $30 \mathrm{~s}, 63^{\circ} \mathrm{C}$ for $45 \mathrm{~s}$, and $72^{\circ} \mathrm{C}$ for $1 \mathrm{~min}$ for 30 cycles, and $72^{\circ} \mathrm{C}$ for $3 \mathrm{~min}$. PCR was performed using Platinum Taq DNA polymerase (Invitrogen) in a Veriti 96 PCR system (ABI, USA). PCR products were separated on $1 \%$ agarose gel. The target gene fragment was recovered by using a commercial gel recovery kit (Omega, USA) and was ligated into pMD18-T for sequencing. Primers containing the restriction digest enzyme sites EcoRI and HindIII were designed for subcloning the FVII cDNA into pcDNA3.1. The ligated product was transformed into $E$. coli $\mathrm{DH} 5 \alpha$. The expression plasmid pcDNA-FVII was selected on Luria-Bertani medium containing $100 \mu \mathrm{g} / \mathrm{mL}$ ampicillin. The plasmid was isolated using a commercially available plasmid extraction kit (Omega), and was further analyzed by EcoRI and HindIII restriction enzyme digestion.

\section{Transfection and selection of stable FVII-expressing cells}

The DNA of pcDNA-FVII was isolated using a commercially available endo-free plasmid extraction kit (Omega). CHO-K1 cells were seeded on 10-cm plates, and upon reaching $70 \%$ confluence were transfected with $1 \mu \mathrm{g}$ Lipo2000 transfection reagent (Invitrogen). The resistance cell colonies were selected with $900 \mu \mathrm{g} / \mathrm{mL}$ G418 (Invitrogen). Stable clones were screened by dilution of the cells and cultured on 96-well plates. The cell culture supernatant was collected and FVII was detected by using an enzyme-linked immunosorbent assay kit (ELISA, Assaypro, USA). The cell line transfected with empty vector pcDNA3.1 (CHOpcDNA3.1) was used as the negative control.

\section{Detection of FVII copy numbers in CHO cells by quantitative PCR (qPCR)}

The genomic DNA of three cell lines expressing FVII was extracted using a DNA extraction kit (Omega). The DNA of cell line CHO-pcDNA3.1 was used as the negative control template. The specific primers were designed to amplify the $\beta$-actin gene from CHO-K1 cells according to the GenBank reference sequence (ID: NW_003613618). These specific primers were: S1, 5'-ACCTGACAGACTACCTCAT-3' and S2, 5'-ACGCACAATTTCCCTCTC-3'. The PCR procedure included an initial denaturation step at $95^{\circ} \mathrm{C}$ for $5 \mathrm{~min}$, followed by $95^{\circ} \mathrm{C}$ for $10 \mathrm{~s}, 60^{\circ} \mathrm{C}$ for $10 \mathrm{~s}$, and $72^{\circ} \mathrm{C}$ for $20 \mathrm{~s}$ for 30 cycles. The PCR product was subcloned to the pMD18-T vector to sequence and obtain the plasmid pMDT-actin; the PCR product of $\beta$-actin was $80 \mathrm{bp}$. The DNA of the pMDT-actin plasmid was quantified to $10^{6}, 10^{5}, 10^{4}, 10^{3}$, and $10^{2}$ copies $/ \mu \mathrm{L}$ in order to make a standard curve for calculating the total cell number of the template. The qPCR system comprised $10 \mu \mathrm{L} 2 \mathrm{X}$ SYBR Green Mix (Bio-Rad, USA), $0.8 \mu \mathrm{L}$ $\mathrm{S} 1,0.8 \mu \mathrm{L} \mathrm{S} 2,1 \mu \mathrm{L}$ DNA, and $7.4 \mu \mathrm{L} \mathrm{ddH}_{2} \mathrm{O}$. The qPCR procedure was as follows: initial de- 
naturation at $95^{\circ} \mathrm{C}$ for $3 \mathrm{~min}, 95^{\circ} \mathrm{C}$ for $10 \mathrm{~s}, 60^{\circ} \mathrm{C}$ for $10 \mathrm{~s}$, and $72^{\circ} \mathrm{C}$ for $20 \mathrm{~s}$ for 40 cycles. The DNA of the pcDNA-FVII plasmid was diluted to $10^{7}, 10^{6}, 10^{5}, 10^{4}$, and $10^{3}$ copies/ $\mu \mathrm{L}$ to make the standard curve for calculating the FVII copy number. The specific primers used for FVII amplification were as follows: F2, 5'-TCCTGTTGTTGGTGAATG-3' and R2, 5'-GTTCCTCC AGTTCTTGATT-3'; the length of the PCR product was $95 \mathrm{bp}$. The qPCR system comprised $10 \mu \mathrm{L} 2 \mathrm{X}$ SYBR Green Mix, $0.8 \mu \mathrm{L}$ F2, $0.8 \mu \mathrm{L} \mathrm{R} 2,1 \mu \mathrm{L}$ DNA, and $7.4 \mu \mathrm{L} \mathrm{ddH}_{2} \mathrm{O}$. The qPCR procedure was as follows: initial denaturation at $95^{\circ} \mathrm{C}$ for $3 \mathrm{~min}, 95^{\circ} \mathrm{C}$ for $10 \mathrm{~s}, 60.3^{\circ} \mathrm{C}$ for $10 \mathrm{~s}$, and $72^{\circ} \mathrm{C}$ for $20 \mathrm{~s}$ for 40 cycles. The concentration and purity of the plasmid were detected by using the NanoVue system (GE, USA). All samples were tested in three biological replicates and three technical replicates. All qPCRs were performed in the Stepone plus system $(\mathrm{ABI})$.

\section{Purification of the rFVII protein by affinity chromatography}

The rFVII was purified by using VIISelect affinity chromatography medium (GE). The culture medium containing FVII was added to the column and the bound protein was eluted according to manufacturer recommendations, using elution buffer comprising $50 \mathrm{mM}$ Tris, $1.5 \mathrm{M} \mathrm{NaCl}$, and $50 \%$ propyleneglycol. The cell culture supernatant transfected with the empty vector pcDNA3.1 was also passed through the column as a negative control.

\section{Detection of the purified protein}

The purified protein was detected by sodium dodecyl sulfate-polyacrylamide gel electrophoresis (SDS-PAGE) on 12\% gels followed by Coomassie blue staining. The protein was then transferred to polyvinylidene fluoride (PVDF) membranes (Hi-bond, Amersham Bioscience, USA). The purified protein was detected using 1:250 mouse anti-human FVII antibody (R\&D Systems, USA) as the first antibody, and with 1:5000 horseradish peroxide-conjugated sheep anti-mouse IgG (Santa Cruz Biotechnology, USA) as the secondary antibody. The total protein concentration was quantified by using a BCA kit (Thermo, USA). The coagulant activity of purified FVII was measured by using FVII-depleted human plasma (Pacific Hemostasis, USA) and thromboplastin preparations (SIEMENS, Germany). The method for detecting the coagulant activity of the purified FVII was as follows: $3876 \mathrm{U} / \mathrm{mg}$ human FVII standard (ADI, USA) was first diluted to $1 \mathrm{U} / \mathrm{mL}$ and then further diluted according to $1 / 5,1 / 10,1 / 20,1 / 40$, and $1 / 80$ to calculate the clotting time and to make the standard curve.

The clotting time of purified rFVII was determined by a prothrombin time assay to calculate the specific activity of the purified FVII. Prothrombin time assays were performed in a full-automatic timer device (Sysmex CA-1500, Japan).

\section{RESULTS}

\section{Cloning of FVII cDNA and construction of the expression vector}

The electrophoresis results showed that an approximately 1335-bp fragment was cloned by RT-PCR (Figure 1). The nucleotide sequence was confirmed by DNA sequencing. The sequencing result demonstrated that the PCR fragment was indeed the full-length cDNA 
sequence of human coagulation factor VII; this gene is accessible in GenBank (accession No. NM_019616.3). The restriction enzyme digestion analysis with EcoRI and HindIII confirmed the presence of the 1335-bp insert fragment (Figure 2).

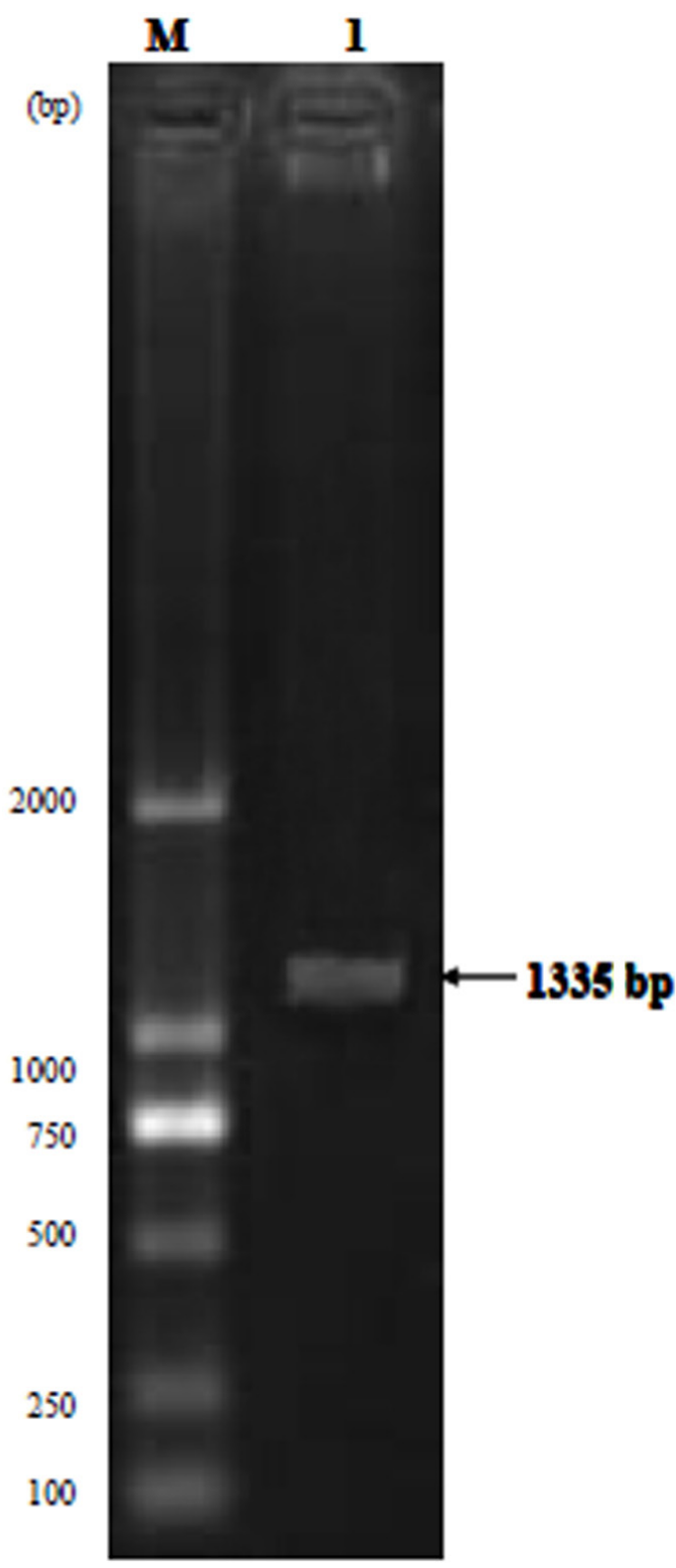

Figure 1. Cloning of human factor FVII by RT-PCR. Lane $M=$ DL2000 ladder marker; lane 1 = full-length FVII cDNA cloned by RT-PCR 


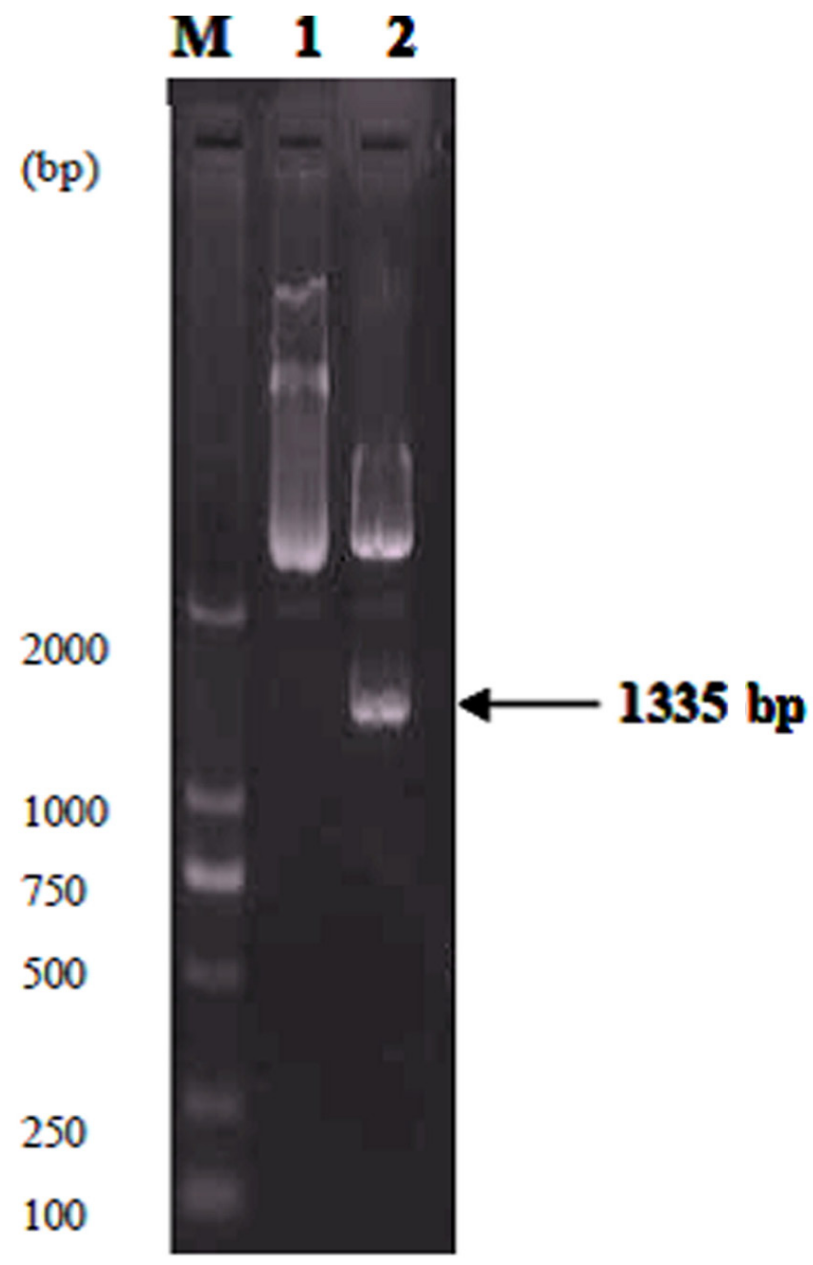

Figure 2. Restriction enzyme digestion analysis of expression plasmid pcDNA-FVII. Lane $M=$ DL2000 ladder marker; lane 1 = expression plasmid pcDNA-FVII; lane 2 = pcDNA-FVII plasmid identified by EcoRI/HindIII digestion.

\section{Detection of the secretory expression of FVII in the CHO cell line}

Three cell lines that showed secretory FVII expression were selected. The FVII concentration in the cell culture supernatant was determined by ELISA. The mean \pm SD expression levels of three replicates of each of the three cell lines, clone 1, clone 2, and clone 3, were $300 \pm 4.5,304 \pm 2.5$, and $302 \pm 1.4 \mathrm{ng} / \mathrm{mL}$, respectively; however, the empty transfected cell vector did not express FVII protein. The accuracy of the expression level was further determined by qPCR to absolutely quantify the FVII copy number in the selected cell lines. The absorbance $(\mathrm{A})_{260} / \mathrm{A}_{280}$ of plasmid pMDT-actin was 1.86, which showed that the purity of the plasmid was suitable. The resulting standard curve for plasmid pMDT-actin showed the following characteristics: $\mathrm{R}^{2}=0.992$, amplification efficiency $=107.3 \%$, slope $=-3.157$, and 
the regression equation was $y=-3.157 x+36.918$ (Figure 3 ). The standard curve of plasmid pcDNA-FVII showed the following characteristics: $\mathrm{R}^{2}=0.992$, amplification efficiency $=$ $93.4 \%$, slope $=-3.49$, and the regression equation was $y=-3.49 x+42.038$ (Figure 4). All results were analyzed by using the Stepone software V2.2 (ABI) to calculate the total cell number and the FVII gene copy number. The analysis results demonstrated that the total cell number in templates was $24,421 \pm 7414$ and the copy number of the FVII gene was $49,455 \pm$ 3502. The melt curve analysis showed that the melting temperature (Tm) of the $\beta$-actin gene is $82.7^{\circ}-83.2^{\circ} \mathrm{C}$ (Figure 5), and the Tm of the FVII gene is $83.9^{\circ}-84.4^{\circ} \mathrm{C}$ (Figure 6). Specific gene amplification could not be detected in negative CHO-pcDNA3.1 templates. The qPCR results clearly showed that each cell harbored two FVII copy numbers.

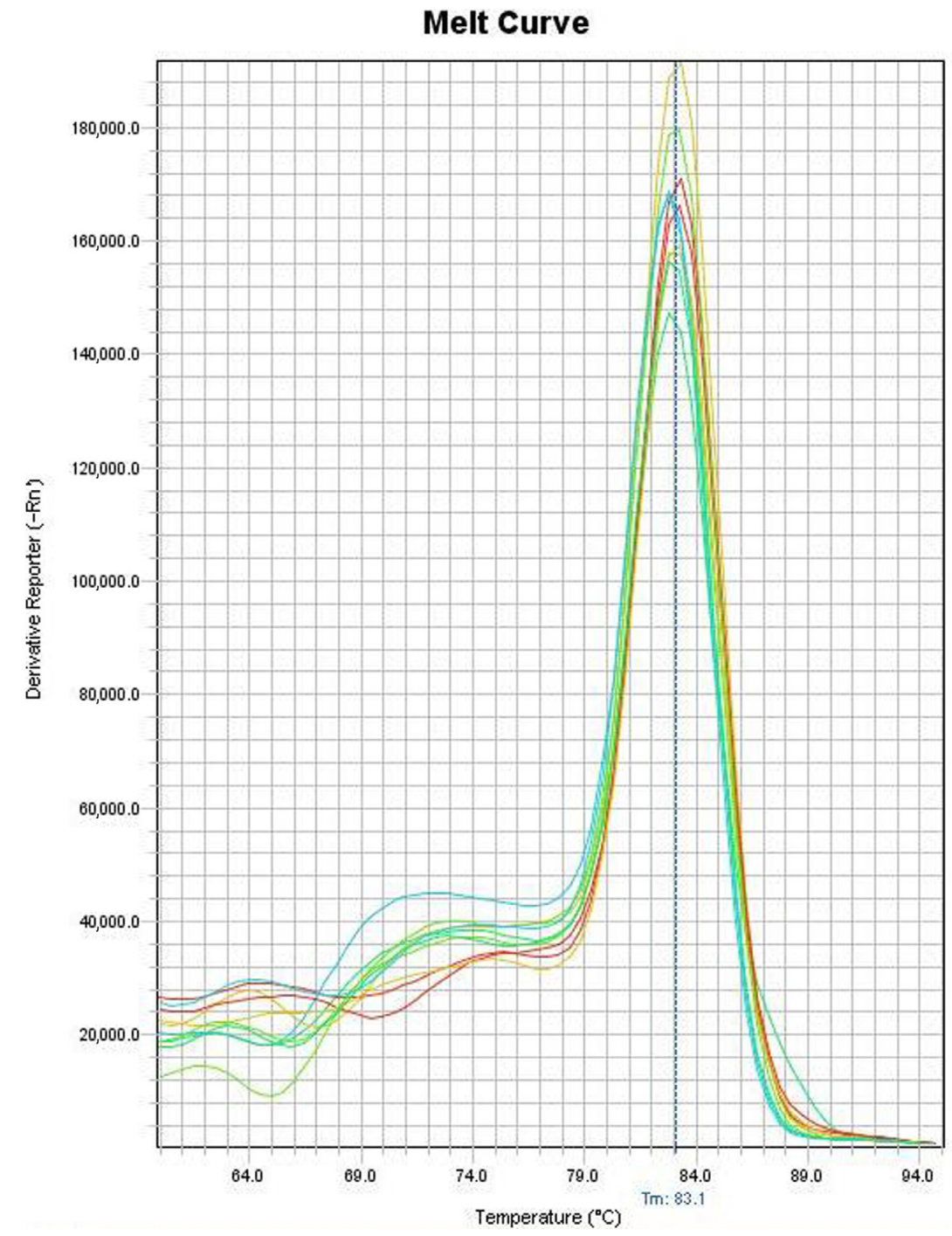

Figure 3. Melt curve analysis of the $\beta$-actin gene. $\mathrm{Tm}=$ melting temperature. 


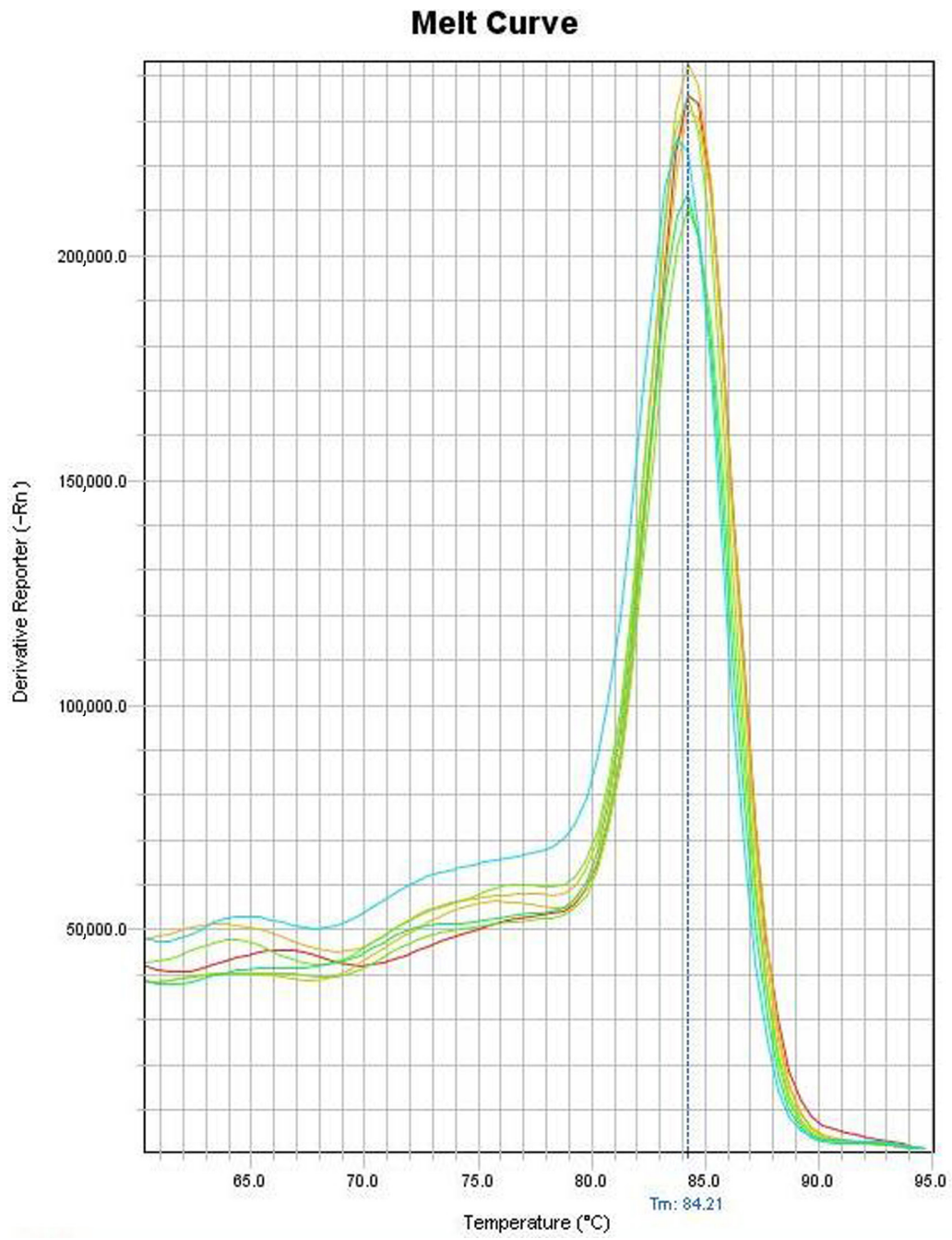

Figure 4. Melt curve analysis of the FVII gene. Tm = melting temperature.

\section{SDS-PAGE and Western blotting analysis of the purified rFVII protein}

The eluted protein was analyzed by SDS-PAGE, Western blotting, and ELISA. A protein of approximately $50 \mathrm{kDa}$ was detected by SDS-PAGE (Figure 5). Western blotting showed that a $50-\mathrm{kDa}$ band was detected in the eluted protein; however, no target band was observed in the elution buffer of the cell culture supernatant transfected with the empty vector pcDNA3.1 (Figure 6).

\section{Specific activity analysis of the purified rFVII}

The clotting time of purified rFVII was determined by a prothrombin time assay to calculate the specific activity of the purified FVII. Dilution factors of the human FVII standard 
$(1 / 5,1 / 10,1 / 20,1 / 40$, and 1/80) corresponded to different FVII:C proportions $(100,50,25$, 12.5 , and $6.25 \%$ ). The standard curve was constructed by plotting the FVII:C on the $\mathrm{x}$-axis and clotting time on the y-axis (Figure 7). Linear regression analysis was performed and the resulting equation had the form $\log \mathrm{Y}=b \log \mathrm{X}+a$. The activity of purified $\mathrm{rFVII}$ was $0.54 \pm 0.01$ $\mathrm{IU} / \mathrm{mL}$ and the total protein concentration was $2.1 \pm 0.1 \times 10^{-4} \mathrm{mg}$. Thus, the specific activity of purified $\mathrm{rFVII}$ was $2573 \pm 75 \mathrm{IU} / \mathrm{mg}$.

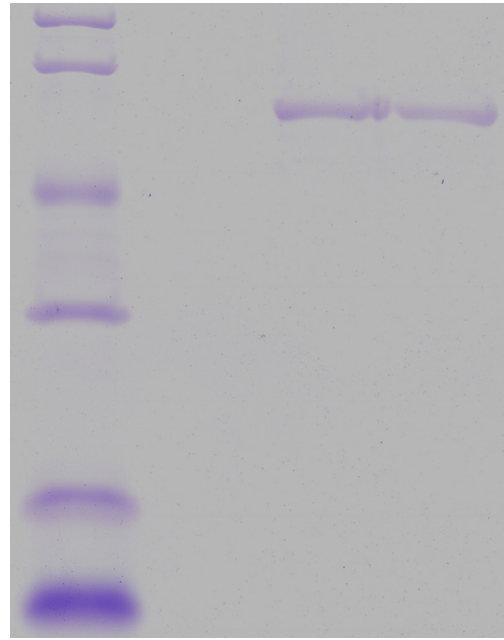

Figure 5. SDS-PAGE analysis of the purified FVII protein. Lane $M=$ low molecular weight protein marker; lane 1 $=$ cell culture supernatant transfected with empty vector pcDNA3.1; lanes 2 and 3 = purified protein from CHO-K1 cells transfected with vector pcDNA-FVII.

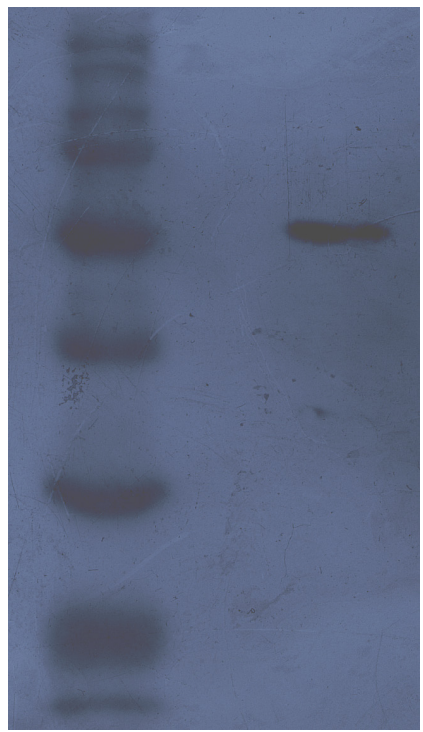

Figure 6. Western blot analysis of the purified FVII protein. Lane $M=$ Western marker; lane 1 = purified protein from $\mathrm{CHO}-\mathrm{K} 1$ cells transfected with empty vector pcDNA3.1; lane 2 = purified protein from $\mathrm{CHO}-\mathrm{K} 1$ cells transfected with vector pcDNA-FVII. 


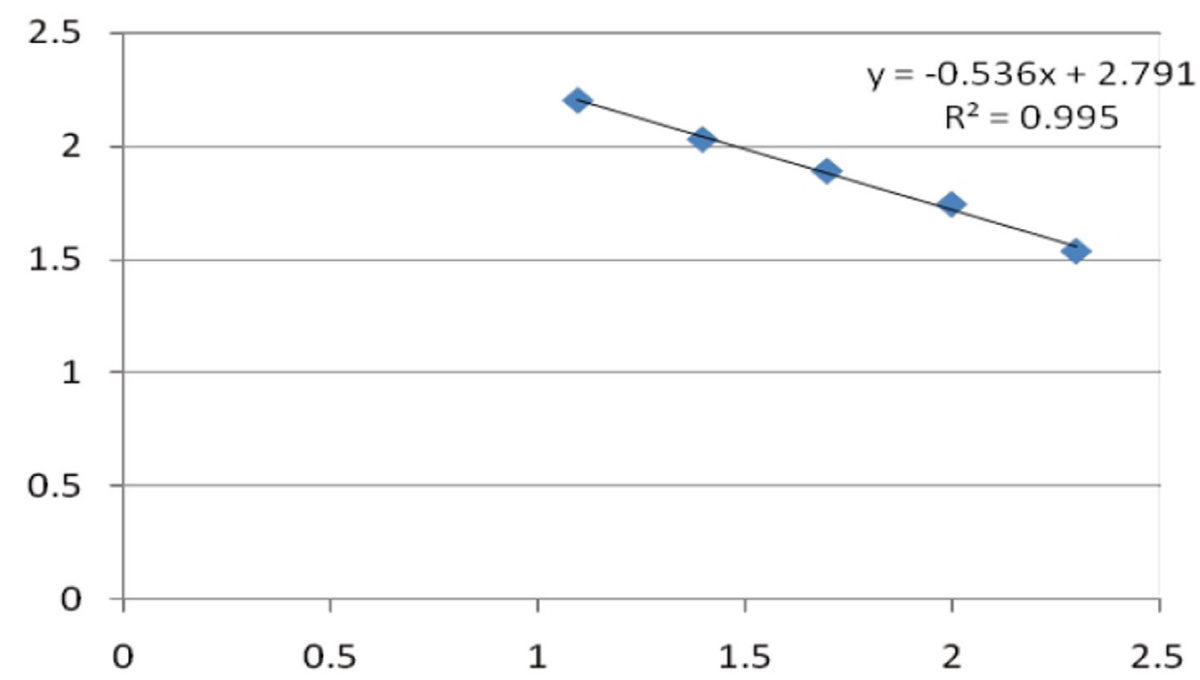

Figure 7. Standard curve of the human coagulation factor VII.

\section{DISCUSSION}

The current study reported the expression and purification of human $\mathrm{rFVII}$ in CHOK1 cells. The purification of rabbit rFVII was reported by Ruiz et al. (2000) who utilized pCMV5 for expressing rabbit rFVII in the human 293 cell line. The rabbit rFVII was purified using a variation of the barium citrate precipitation technique followed by DEAE sepharose FF and benzamidine agarose column chromatography (Gassmann et al., 1990; Ruiz et al., 2000). Commercially available human rFVIIa (NovoSeven) was produced in BHK cells and purified by consecutive chromatography steps, including immunoaffinity chromatography, by using murine monoclonal antibodies (Halabian et al., 2009). In our study, the rFVII was purified by using a new affinity chromatography medium, VIISelect. VIISelect is based on porous, spherical agarose particles (the base matrix) with a covalently attached FVII binding protein (the ligand); the ligand itself was developed using Camelidae-derived single-domain antibody fragments from the immune response of llamas toward the target human FVII molecule. The ligand can specifically bind human recombinant coagulation factor VII. This medium can reduce regulatory concerns owing to the non-mammalian-derived product in the production of FVII for clinical applications. SDS-PAGE showed that the 50-kDa protein was detected, and Western blotting further confirmed that the 50-kDa protein was the recombinant human coagulation factor VII. The 50-kDa rFVII protein was detected as a single band by SDS-PAGE. The purity of rFVII was $95 \%$, which indicated that this method could be used to obtain high-purity rFVII and might obviate the additional purification steps.

Specific activity evaluation was performed using a full-automatic timer device (Sysmex CA-1500) during the process of activity testing to obtain more accurate results. The results demonstrated that the specific activity of rFVII was $2570 \mathrm{IU} / \mathrm{mg}$. This showed that the purified rFVII protein had biological function.

The copy number of foreign genes in a host cell is a very important parameter for 
evaluating the expression level of recombinant proteins (Jiang et al., 2006). The traditional methods of cell copy number quantification are Southern blot (Huang et al., 1992) and capillary electrophoresis (Hinnebusch and Barbour, 1992). Execution of the above-mentioned methods are complex and the results are only semi-quantitative. The development of fluorescence qPCR technology provides a quicker and easier method for detecting the copy number in different samples; hence, it has been widely used in many research fields (Higgins et al., 2001; Yang et al., 2005). In the current study, we established a method for detecting the FVII copy number by using SYBR GreenI in CHO-K1 cells. The melt curve analysis indicated a single-PCR product and demonstrated improved specificity of the primers. The linearity of the standard curve was 0.992 , and the amplification efficiency of the standard curve was 107 and $93.4 \%$, respectively. The preparation of the standard curve, therefore, met the requirements. The qPCR results demonstrated that each CHO-K1 cell only harbored two FVII gene copies. The FVII expression amount in the selected CHO-K1 cell line was determined to be approximately $300 \mathrm{ng} / \mathrm{mL}$. These results suggest that the construction of vectors (Girod et al., 2005; Wang et al., 2008) should be used in future research to increase the copy number in CHO-K1 cells and thereby improve expression levels.

\section{CONCLUSION}

In this research, rFVII was successfully cloned and expressed in CHO-K1 cells. A new affinity chromatography medium was used to purify FVII from the cell culture supernatant. The results revealed that the purified rFVII protein was biologically active.

\section{ACKNOWLEDGMENTS}

We thank Dr. Joy Cheng for her help in preparing this manuscript.

\section{REFERENCES}

Gassmann M, Thommes P, Weiser T and Hubscher U (1990). Efficient production of chicken egg yolk antibodies against a conserved mammalian protein. FASEB J. 4: 2528-2532.

Girod PA, Zahn-Zabal M and Mermod N (2005). Use of the chicken lysozyme 5' matrix attachment region to generate high producer CHO cell lines. Biotechnol. Bioeng. 91: 1-11.

Halabian R, Fathabad ME, Masroori N, Roushandeh AM, et al. (2009). Expression and purification of recombinant human coagulation factor VII fused to a histidine tag using Gateway technology. Blood Transfus. 7: 305-312.

Hedner U and Lee CA (2011). First 20 years with recombinant FVIIa (NovoSeven). Haemophilia 17: e172-e182.

Higgins JA, Fayer R, Trout JM, Xiao L, et al. (2001). Real-time PCR for the detection of Cryptosporidium parvum. J. Microbiol. Methods 47: 323-337.

Hinnebusch J and Barbour AG (1992). Linear- and circular-plasmid copy numbers in Borrelia burgdorferi. J. Bacteriol. 174: 5251-5257.

Huang M, Liu S, Murray BK and Lee ML (1992). High resolution separation and quantitation of ribonucleotides using capillary electrophoresis. Anal. Biochem. 207: 231-235.

Jiang Z, Huang Y and Sharfstein ST (2006). Regulation of recombinant monoclonal antibody production in chinese hamster ovary cells: a comparative study of gene copy number, mRNA level, and protein expression. Biotechnol. Prog. 22: 313-318.

Kisiel W and Davie EW (1975). Isolation and characterization of bovine factor VII. Biochemistry 14: 4928-4934.

Kisiel W, Fujikawa K and Davie EW (1977). Activation of bovine factor VII (proconvertin) by factor XIIa (activated Hageman factor). Biochemistry 16: 4189-4194.

O'Hara PJ, Grant FJ, Haldeman BA, Gray CL, et al. (1987). Nucleotide sequence of the gene coding for human factor 
VII, a vitamin K-dependent protein participating in blood coagulation. Proc. Natl. Acad. Sci. U. S. A. 84: 5158-5162. Radcliffe R, Bagdasarian A, Colman R and Nemerson Y (1977). Activation of bovine factor VII by hageman factor fragments. Blood 50: 611-617.

Ruiz SM, Sridhara S, Blajchman MA and Clarke BJ (2000). Expression and purification of recombinant rabbit factor VII. Thromb. Res. 98: 203-211.

Seligsohn U, Osterud B, Brown SF, Griffin JH, et al. (1979). Activation of human factor VII in plasma and in purified systems: roles of activated factor IX, kallikrein, and activated factor XII. J. Clin. Invest. 64: 1056-1065.

Wang TY, Yang R, Qin C, Wang L, et al. (2008). Enhanced expression of transgene in CHO cells using matrix attachment region. Cell Biol. Int. 32: 1279-1283.

Yang FL, Jia WX, Yue H, Luo W, et al. (2005). Development of quantitative real-time polymerase chain reaction for duck enteritis virus DNA. Avian Dis. 49: 397-400. 